\title{
PHENOLIC COMPOSITION AND ANTIOXIDANT ACTIVITIES OF CLADODES OF THE TWO VARIETIES OF CACTUS PEAR (OPUNTIA FICUS-INDICA) GROWN IN ETHIOPIA
}

\author{
Kiros Haile ${ }^{1,2}$, Bewketu Mehari ${ }^{3}$, Minaleshewa Atlabachew ${ }^{4}$ and \\ Bhagwan Singh Chandravanshi ${ }^{1 *}$ \\ ${ }^{1}$ Department of Chemistry, College of Natural Sciences, Addis Ababa University, P.O. Box \\ 1176, Addis Ababa, Ethiopia \\ ${ }^{2}$ Department of Chemistry, Faculty of Science, Wolaita Sodo University, P.O. Box 138, \\ Wolaita Sodo, Ethiopia \\ ${ }^{3}$ Department of Chemistry, College of Natural and Computational of Sciences, University of \\ Gondar, P.O. Box 196, Gondar, Ethiopia \\ ${ }^{4}$ Department of Chemistry, College of Natural Sciences, Bahir Dar University, P.O. Box 79, \\ Bahir Dar, Ethiopia
}

(Received December 17, 2015; revised September 11, 2016)

\begin{abstract}
In this study, young cladodes corresponding to two (thorn-less and thorn-containing) varieties of cactus pear (Opuntia ficus-indica) from four different areas of Tigray region, Ethiopia, were investigated for their phenolic contents and antioxidant activities. Quantitative estimation of total phenolic contents and antioxidant activities in the cladodes was carried out using spectrophotometric methods. A 1,1-diphenyl-2-picrylhydrazyl (DPPH) scavenging assay was used for the determination of the antioxidant activities, while Folin-Ciocalteau reagent, aluminum chloride and protein (albumin) precipitation methods were used for the determination of total polyphenol, flavonoid and tannin contents, respectively. The cladodes were found to be rich in polyphenols, with values in the range 18.0-71.4 mg gallic acid equivalent (GAE)/g of dry weight (DW). The predominant part of the polyphenols is represented by tannins, $9.00-41.2 \mathrm{mg}$ GAE$/ \mathrm{g}$ of DW, followed by flavonoids, $6.40-25.0 \mathrm{mg}$ catchin equivalent $(\mathrm{CE}) / \mathrm{g}$ of DW. The cladodes showed strong antioxidant activities, 59.3-85.8\% inhibition compared to ascorbic acid. Application of paired t-test on the overall mean total polyphenol contents of samples collected from the different areas revealed the presence of significant variation between the thorn-less (31.6 $\mathrm{GAE} / \mathrm{g}$ of DW) and thorn-containing (47.7 GAE/g of DW) varieties. One-way ANOVA also revealed that there are significant variations among samples from the same variety but collected from different areas.
\end{abstract}

KEY WORDS: Opuntia ficus-indica, Flavonoids, Tannins, Polyphenols, Antioxidant activities, Ethiopia

\section{INTRODUCTION}

In recent decades, studies have been focused on foods rich in phytochemical and functional properties. Many studies have indicated a positive correlation between consumption of plant foods and reducing the risks of some diseases such as cancer, cardiovascular diseases, or diabetes [1]. This relation is in most cases attributed to high contents of phenolic compounds and their respective antioxidant activities [2]. Phenolic compounds are widely distributed in many fruits and vegetables. Their type, concentration and hence their biological activity varied with plant species [1-4].

Cactus pear (Opunta ficus-indica) or prickly pear, a member of the Cactaceae family, is widely distributed in Mexico and in all American hemispheres and grows in many other parts of the world, such as Africa, Australia, Europe and the Mediterranean basin [5]. There are several species belonging to the genus Opuntia (Family Cactaceae). This includes O. Ficus-indica, $O$. dillenii, O. robusta, O. Tormentosa and O. tuna. Of these, O. ficus-indica is the most common

*Corresponding author. E-mail: bscv2006yahoo.com 
species that is grown in Ethiopia [6-8]. Cactus pear (O. ficus-indica) is commonly known in Ethiopia as "Beles" $[6,9]$.

The farmers of northern Ethiopia identified several locally grown varieties of cactus pear that varied in their morphological characteristics. Among these characteristics, the presence or absence of spines is one of the basic parameters to identify the cladodes varieties [9].

Cactus pears were largely ignored by the scientific community until the beginning of the 1980s when several studies and reports were published on their biological functions. More recent investigations on the chemical components and the nutritional value of Opuntia have attracted attention in the food, nutritional and even pharmacological sciences $[6,8,10-12]$.

In the past only the fruit was considered to be nutritious and the leaves were used for animal feed. However, recently, the young leaves (cladodes) of $O$. ficus-indica is found to be nutritious and believed to have medicinal property. Freshly harvested cactus pear cladodes are regarded as vegetables; they present a high content of water and a minor proportion of dietary fiber, lipids, proteins and calcium. Other constituents are antioxidants, such as ascorbic acid, phenolic compounds, $\beta$-carotene, lutein and xanthophylls [13-17]. This part of the plant is known for its medicinal properties, such as an auxiliary treatment for obesity, and gastrointestinal or cardiovascular disorders. These extracts also decrease the levels of cholesterol and serum glucose $[18,19]$. But, due to lack of well documented information about its nutritional quality, cactus pear is underutilized plant in Ethiopia and it has not been used as an alternative source of food nutrition in different parts of the country.

Few papers have been reported on the antioxidant activity and phenolic composition of cladodes of $O$. ficus-indica grown in the overseas. As per the report of Dib et al. [15], the composition of phenolic compounds of cladodes of $O$. ficus-indica is found to be: total polyphenols $26.7 \pm 0.2$ (mg GAE/g DW), flavonoids $11.9 \mathrm{mg} \mathrm{CE} / \mathrm{g} \mathrm{DW}$ and total tannin $6.45 \pm 0.11$ (mg GAE/g DW). Furthermore the composition of different extracts of Algerian cladode of $O$. ficus-indica was reported in terms of $\mathrm{IC}_{50}(\mathrm{mg} / \mathrm{mL})$ values as polyphenols total $0.6 \pm 0.1$, flavonoids (ethyl ether) $5.3 \pm 0.02$, flavonoids (ethyl acetate) $1.81 \pm 0.01$, flavonoids (nbutanol) $4.87 \pm 0.06$, tannins $0.95 \pm 0.007$ and ascorbic acid $0.13 \pm 0.002$ [15].

However, there is no such report on Ethiopian O. ficus-indica. It has to be noted that plant nutrients are dependent on the type of the plant species, soil type, geographical location, over all climatic conditions of the region, harvesting season and maturity stage of the plant. Thus, the

aim of this study was to investigate the phenolic composition (total polyphenol, flavonoid and tannin) and antioxidant activity of $O$. ficus-indica grown in Ethiopia.

\section{EXPERIMENTAL}

\section{Chemicals and reagents}

All the chemicals and reagents used in this study were of analytical grade reagents with highest purity. These chemicals and reagents were: anhydrous sodium carbonate (Research Lab Fine Chem Industries, Mumbai, India); L-ascorbic acid 98\% (Vitamin C, BDH Chemicals Ltd., Pool, England); sodium molybdate dehydrate 98\% (BDH Laboratories Supplies, Poole, England); anhydrous sodium sulfate (Research-Lab Fine Chem Industries, Mumbai, India); anhydrous aluminum chloride and sodium nitrite (Fluka, Switzerland); ovalbumin, sodium carbonate decahydrate and ethanol (Research Lab Fine Chem, Mumbai, India); sodium acetate, sodium hydroxide and ascorbic acid (BDH, England); D-catechin, hydrochloric acid, 1,1-diphenyl-2picrylhydrazyl and methanol (Sigma Aldrich); sodium tungstate dihydrate and phosphomolybdic acid (Scharlau Chemie, Spain). 
Phenolic composition and antioxidant activities of cladodes of two varieties of cactus pear 349

Apparatus and equipments

Electronic blending device (Moulinex, France), electronic balance (WL 3000, Adam Equipment Co. Ltd., UK), Whatman ${ }^{\circledR}$ filter paper $110 \mathrm{~mm}$ (Whatman International Ltd, Maid-Stone, England), pipettes (Pyrex, USA), micropipettes (Dragonmed, 10-100 $\mu \mathrm{L}$, Shangai, China) and UV-VIS spectrophotometer (Perkin Elmer Lambda 900, USA) were used in the study.

\section{Collection of plant material}

Samples from two different varieties (thorn-less and thorn-containing) of cactus pear cladodes were collected from farm fields in four districts (weredas) of Tigray (Ethiopia). The cladodes were grown without using any fertilizer during the summer. From each of the four districts, samples of $4 \mathrm{~kg}$ each of prickly pads of the cladodes, corresponding to each of the two varieties, were collected from four different sites at different maturity stages. Thirty two cladodes from eight plants (four cladodes from one plant) were collected from each sampling site to prepare bulk samples. Accordingly, a total of eight bulk samples, four from each variety were collected. The geographical locations of the sampling areas are given in Table 1. A clean plastic knife was used to cut the sample material from the mother cladodes. All the samples were collected in polyethylene plastic bags.

The sampling areas were chosen based on their commercial importance and for their high production and consumption of the fruits of the cladodes of cactus pear by the local people in the region. Besides, many parts of the selected areas are covered by these specific plant varieties.

Table 1. Geographical location of the sample areas.

\begin{tabular}{|l|c|c|c|}
\hline Sample area & Longitude & Latitude & Altitude (m) \\
\hline Adigrat & $39^{\circ} 27^{\prime} 39^{\prime \prime} \mathrm{E}$ & $14^{\circ} 16^{\prime} 37^{\prime \prime} \mathrm{N}$ & 2,457 \\
\hline Addishihu & $39^{\circ} 31^{\prime} 1 " \mathrm{E}$ & $12^{\circ} 56^{\prime} 3^{\prime \prime} \mathrm{N}$ & 1,324 \\
\hline Mekhoni & $39^{\circ} 38^{\prime} 44^{\prime \prime} \mathrm{E}$ & $12^{\circ} 47^{\prime} 55^{\prime \prime} \mathrm{N}$ & 1,520 \\
\hline Machew & $39^{\circ} 32^{\prime} 35^{\prime \prime} \mathrm{E}$ & $12^{\circ} 47^{\prime} 2^{\prime \prime} \mathrm{N}$ & 2,479 \\
\hline
\end{tabular}

\section{Sample preparation}

The nopal pads of the cladodes of cactus pear were washed with distilled water and disinfected using commercial $10 \%$ sodium hypochlorite solution in order to eliminate microorganisms. The thorns of the plant material were removed manually and the pads were cut into small slices in order to facilitate the drying process. The prickly pads were air dried in an open room at room temperature for three weeks. Finally, the prickly pads were pulverized to fine powder and stored at room temperature until analysis.

\section{Extraction of the plant material for phenolic analysis}

The dried and ground cladodes $(10 \mathrm{~g})$ were extracted with $200 \mathrm{~mL}$ of methanol-water $(70 / 30$, $\mathrm{v} / \mathrm{v}$ ) by maceration at room temperature for 24 hours. Then the extracts were filtered through Whatman No. 1 filter paper. Finally, the filtrate was stored in a refrigerator at $4{ }^{\circ} \mathrm{C}$ for further investigation and analysis.

\section{Preparation of Folin-Ciocalteau reagent}

Folin-Ciocalteau reagent was prepared following the procedure reported by Bizuayehu et al. [20]. 


\section{Estimation of total polyphenols}

The total polyphenol content was determined using the Folin-Ciocalteu method, which is based on the reduction of phosphotungstate-phosphomolybdate complex by phenolic compounds into a blue reaction product that can absorb visible radiation at $760 \mathrm{~nm}$ [21]. An aliquot of $0.20 \mathrm{~mL}$ of the extract was mixed with $200 \mu \mathrm{L}$ of Folin-Ciocalteau reagent, which was previously diluted with double distilled water (1:9). The mixture was allowed to stand for $5 \mathrm{~min}$, and then $2.0 \mathrm{~mL}$ of sodium carbonate $(10 \%, \mathrm{w} / \mathrm{v})$ was added to the mixture. Finally, the mixture was allowed to stand in dark place for about $90 \mathrm{~min}$ and the absorbance was measured at $760 \mathrm{~nm}$ against a blank solution using a UV/Visible spectrophotometer. All the measurements were carried out in triplicate and results were expressed as milligram of gallic acid equivalent per gram of dry weight (mg GAE/g DW).

\section{Estimation of total flavonoids}

The total flavonoids content in the plant extracts was estimatedusing aluminum chloride assay $[22,23]$. Briefly, an aliquot $(1.0 \mathrm{~mL})$ of the extract was added to a $10 \mathrm{~mL}$ volumetric flask containing $4.0 \mathrm{~mL}$ of double distilled water. To this flask $0.3 \mathrm{~mL}$ of $5 \% \mathrm{NaNO}_{2}$ was added. After $5 \mathrm{~min}$ of incubation, $0.3 \mathrm{~mL} 10 \% \mathrm{AlCl}_{3}$ was added. At the $6^{\text {th }} \mathrm{min}, 2.0 \mathrm{~mL}$ of $1.0 \mathrm{M} \mathrm{NaOH}$ was added and the volume was adjusted to $10 \mathrm{~mL}$ with water. After $10 \mathrm{~min}$, the absorbance of the resulting solution was measured at $510 \mathrm{~nm}$. Catechin was used as a calibrator standard. Catechin was used as standard to express total flavonoid contents of samples as mg catechin equivalent per gram of dry weight ( $\mathrm{mg} \mathrm{CE} / \mathrm{g}$ of DW) [24].

\section{Estimation of total tannins}

The content of total tannin was estimated by protein precipitation method reported by Atlabachew et al. [25] using egg albumin to precipitate tannins in the plant extracts. A portion of $1.0 \mathrm{~mL}$ the sample extract was transferred into a centrifuge tube and mixed with $2.0 \mathrm{~mL}$ of $5.0 \mathrm{mg} / \mathrm{mL}$ egg albumin in acetate buffer solution $(0.1 \mathrm{M}, \mathrm{pH}, 4.6)$. The mixture was incubated for about $15 \mathrm{~min}$ at room temperature, centrifuged at $2000 \mathrm{rpm}$ for $10 \mathrm{~min}$ and the supernatant was filtered and used to estimate the non-tannins phenolics.

An aliquot of $200 \mu \mathrm{L}$ of the supernatant (tannin free) was taken and mixed with $2.0 \mathrm{~mL}$ of Folin-Ciocalteau reagent, which was previously diluted with (1:9) double distilled water. A 2 $\mathrm{mL}$ of $7 \%(\mathrm{w} / \mathrm{v})$ sodium carbonate solution $\left(\mathrm{Na}_{2} \mathrm{CO}_{3}\right)$ was added in to the mixture, and the volume was adjusted to $10 \mathrm{~mL}$ by adding distilled water. The absorbance of the solution was measured using at $760 \mathrm{~nm}$. The tannin concentration was obtained by difference (before and after precipitation by protein). Calibration curve was constructed using gallic acid solution in water to express results as $\mathrm{mg} \mathrm{GAE} / \mathrm{g}$ of DW.

\section{Determination of antioxidant activity}

The antioxidant activity of the cladodes extracts were evaluated using DPPH method reported by Yeddes et al. [26] with little modification. A mass of $0.04 \mathrm{~g}$ of DPPH was dissolved with a small amount of methanol in a $250 \mathrm{~mL}$ volumetric flask. After the DPPH was fully dissolved the flask was filled up to $250 \mathrm{~mL}$ using methanol. The control was measured using $3 \mathrm{~mL}$ of methanol and $2 \mathrm{~mL}$ of DPPH solution. Besides, a stock solution of ascorbic acid was prepared by dissolving $0.02 \mathrm{~g}$ of ascorbic acid in $100 \mathrm{~mL}$ of water. Generation of standard curve was achieved by preparing different concentrations, $25.0,12.5,6.25,3.125$ and $1.56 \mathrm{mg} / \mathrm{L}$, from the stock solution. From each standard solution of ascorbic acid a volume of $1 \mathrm{~mL}$ was transferred in to five different test tubes. To each test tube $3 \mathrm{~mL}$ of methanol and $2 \mathrm{~mL}$ of DPPH solution 
was added, the test tubes were covered by paraffin and kept in the dark for 1 hour. Finally the absorbance was measured at $517 \mathrm{~nm}$. For the samples, a $2 \mathrm{~mL}$ portion of the extract was mixed with $3 \mathrm{~mL}$ of methanol and $2 \mathrm{~mL}$ of DPPH. The mixture was kept in the dark for 1 hour. The absorbance was recorded at $517 \mathrm{~nm}$. The results are expressed as $\mathrm{mg}$ ascorbic acid equivalent/g of dry weight. The percentage inhibition of the DPPH radical was also calculated [27]. Each sample was analyzed in triplicate.

Statistical analysis

Results are presented as mean \pm SD from three replicate measurements. One-way ANOVA and paired t-test using IBM SPSS Statistics 20 was used to verify whether there are significant differences in the data obtained from different sampling areas and samples from different varieties of cladodes, respectively. Differences were considered significant when $\alpha<0.05$.

\section{RESULTS AND DISCUSSION}

\section{Total polyphenols}

It has been well documented that the polyphenol content of plant materials is strongly associated with their antioxidant capacity [28]. Phenolics are the principal plant compounds with antioxidant capacity attributable to their redox properties, which exhibit an important function in neutralizing free radicals [29].

The results of the determination of total phenolics are given in Table 2. The total polyphenol content of the cladodes varies in the range 18.0-71.4 mg GAE/g of DW across the different sampling areas and varieties. The concentration of polyphenols found in Ethiopian cladodes is much higher than those (3.82-5.71 mg GAE/g of DW) reported by Ramirez-Moreno et al. [30] on the level of polyphenols in cladodes of the two varieties. On the other hand, the amount (26.7 $\mathrm{mg} \mathrm{GAE} / \mathrm{g}$ of DW) reported by Dib et al. [15] fall in the range found in Ethiopian cladodes.

The extracts of cladodes of $O$. ficus-indica were found to have varied level of total polyphenol contents among the sampling sites and varieties (Table 2 and 3). The total polyphenol content ranged from $18.0 \pm 0.55$ to $47.5 \pm 0.63 \mathrm{mg} \mathrm{GAE} / \mathrm{g}$ and $23.0 \pm 0.54$ to $71.4 \pm 2.4$ $\mathrm{mg}$ GAE/g of DW in the thorn-less and thorn-containing cladodes varieties, respectively. The thorn-less cladodes samples from Adigrat and Addishihu showed higher total polyphenol contents, with mean value of 47.5 and $36.5 \mathrm{mg} \mathrm{GAE} / \mathrm{g}$ of $\mathrm{DW}$, respectively, followed by samples from Mekhoni (24.0 mg GAE/g of DW) while the lower values were recorded for samples collected from Machew (18.0 mg GAE/g of DW). One-way ANOVA Duncan's multiple range test revealed that there is significant difference between thorn-less cladodes samples collected from different areas. The observed difference might be attributable to differences in climatic factors and soil chemistry of the regions.

A similar trend was also observed for the thorn-containing variety of $O$. ficus-indica cladodes. The decreasing order of total polyphenol contents of thorn-containing cladodes follow: Addishihu $>$ Adigrat $>$ Mekhoni $>$ Machew. One-way ANOVA showed that the total polyphenol contents differ significantly between the studied sample regions indicating that these chemical constituents are highly affected by geographical origin variation.

For samples from the same sampling areas, effect of variety on the level of phenolic composition was also compared using paired t-test statistical tool. It was observed that the thorn-containing cladodes found to contain significantly higher concentration of total polyphenol than thorn-less cladodes collected from the same areas. This signifies that varietal difference has significant effect on the cladodes phytochemical composition. Application of paired t-test on the overall mean total polyphenol contents of samples collected from the 
different areas revealed the presence of significant variation between the thorn-less $(31.6 \mathrm{GAE} / \mathrm{g}$ of DW) and thorn-containing (47.7 GAE/g of DW) varieties (Figure 1).

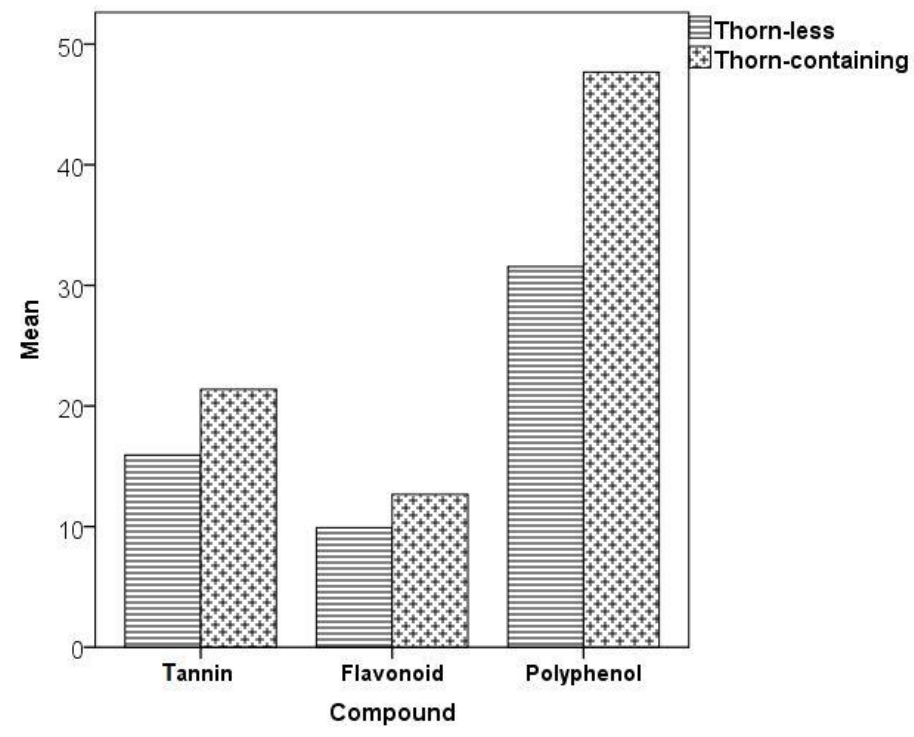

Figure 1. Bar graph showing the total tannin, flavonoid and polyphenol composition of the thorn-less and thorn-containing cladodes of $O$. Ficus-indica grown in Ethiopia.

Table 2. Total polyphenols, flavonoids and tannins contents of thorn-less cladodes of O. Ficus-indica*

\begin{tabular}{|l|c|c|c|}
\hline Sampling area & $\begin{array}{c}\text { Polyphenols } \\
\text { mg GAE/g of DW }\end{array}$ & $\begin{array}{c}\text { Flavonoids } \\
\text { mg CE/g of DW }\end{array}$ & $\begin{array}{c}\text { Total tannin } \\
\text { mg GAE/g of DW }\end{array}$ \\
\hline Addishihu & $36.5 \pm 1.4^{\mathrm{a}}$ & $13.1 \pm 1.8^{\mathrm{d}}$ & $15.0 \pm 0.8^{\mathrm{a}}$ \\
\hline Adigrat & $47.5 \pm 0.6^{\mathrm{b}}$ & $9.60 \pm 0.6^{\mathrm{b}}$ & $25.6 \pm 1.6^{\mathrm{b}}$ \\
\hline Machew & $18.0 \pm 0.6^{\mathrm{c}}$ & $6.40 \pm 0.2^{\mathrm{c}}$ & $9.00 \pm 0.5^{\mathrm{c}}$ \\
\hline Mekhoni & $24.2 \pm 1.5^{\mathrm{d}}$ & $10.5 \pm 0.7^{\mathrm{b}}$ & $14.2 \pm 1.3^{\mathrm{a}}$ \\
\hline
\end{tabular}

*Similar letters within a column indicates absence of significant difference.

Table 3. Total polyphenols, flavonoids and tannins contents of thorn-containing cladodes of O. Ficusindica* ${ }^{*}$.

\begin{tabular}{|l|c|c|c|}
\hline Sampling area & $\begin{array}{c}\text { Polyphenols } \\
\text { mg GAE/g of DW }\end{array}$ & $\begin{array}{c}\text { Flavonoids mg CE/g of } \\
\text { DW }\end{array}$ & $\begin{array}{c}\text { Total tannin } \\
\text { mg GAE/g of DW }\end{array}$ \\
\hline Addishihu & $71.4 \pm 2.4^{\mathrm{a}}$ & $25.0 \pm 1.2^{\mathrm{a}}$ & $41.2 \pm 1.7^{\mathrm{a}}$ \\
\hline Adigrat & $67.4 \pm 1.9^{\mathrm{b}}$ & $10.9 \pm 0.5^{\mathrm{b}}$ & $22.1 \pm 3.4^{\mathrm{b}}$ \\
\hline Machew & $23.0 \pm 0.5^{\mathrm{c}}$ & $7.30 \pm 1.6^{\mathrm{c}}$ & $9.10 \pm 3.0^{\mathrm{c}}$ \\
\hline Mekhoni & $28.9 \pm 1.2^{\mathrm{d}}$ & $7.50 \pm 0.4^{\mathrm{c}}$ & $13.1 \pm 1.3^{\mathrm{d}}$ \\
\hline
\end{tabular}

* Similar letters within a column indicates absence of significant difference.

\section{Total flavonoids}

The total flavonoid contents of the cladode samples are given in Table 2 and 3 as milligram catechin equivalent per gram of dry weight $(\mathrm{mg} \mathrm{CE} / \mathrm{g}$ of $\mathrm{DW})$. The concentration of total 
flavonoids in the cladode was found in the range of 6.44 to 13.1 and 7.29 to $25.0 \mathrm{mg} \mathrm{CE} / \mathrm{g}$ of DW corresponding to the thorn-less and thorn-containing varieties, respectively.

Among samples of the thorn-less variety grown in the different areas, the highest mean concentration of total flavonoids was found in Addishihu (13.1 mg CE/g of DW) followed by Mekhoni (10.5 mg CE/g of DW), Adigrat (9.62 mg CE/g of DW) and Machew (6.44 mg CE/g of DW) (Table 2). The observed variations among the sampling areas are statistically significant except between samples from Mekhoni and Adigrat.

A similar trend was observed for the cladodes of the thorn-containing variety (Table 3 ). The highest total flavonoid content was recorded in thorn-containing cladodes from Addishihu (25.0 $\mathrm{mg} \mathrm{CE} / \mathrm{g}$ of DW) district while the lowest was obtained in samples from Machew $(7.30 \mathrm{mg}$ $\mathrm{CE} / \mathrm{g}$ of DW).

Application of paired t-test on the overall mean total flavonoid contents of samples collected from the different areas revealed the presence of significant variation between the thorn-less (9.90 $\mathrm{mg} \mathrm{CE} / \mathrm{g}$ of DW) and thorn-containing (12.7 mg CE/g of DW) varieties (Figure 1). While pair wise comparison revealed the highest variation between the thorn-less $(13.1 \mathrm{mg} \mathrm{CE} / \mathrm{g}$ of DW) and thorn-containing (25.0 $\mathrm{mg} \mathrm{CE} / \mathrm{g}$ of DW) samples from Addishihu. Unlike samples from Addishihu, the flavonoid content of the thorn-less $(10.5 \mathrm{mg} \mathrm{CE} / \mathrm{g}$ of DW) cladodes from Mekhoniare found to be significantly higher than the corresponding thorn-containing $(7.50 \mathrm{mg}$ $\mathrm{CE} / \mathrm{g}$ of DW) variety.

Relatively higher concentrations of flavonoids were obtained in some of the studied samples compared to that (11.9 mg CE/g of DW) reported by Dib et al. [15]. The total flavonoid content ( $25.0 \mathrm{mg} \mathrm{CE} / \mathrm{g}$ of DW) of the thorn-containing samples from Addishihu is much higher than that reported by $\mathrm{Dib}$ et al. [15]. Comparable results were noticed in thorn-less samples from Addishihu, and Mekhoni as well as thorn-containing samples from Adigrat with the report by Dib et al. [15]. On the other hand, significantly lower concentration of flavonoids were noticed in both thorn-less $(6.50 \mathrm{mg} \mathrm{CE} / \mathrm{g}$ of DW) and thorn-containing (7.30 $\mathrm{mg} \mathrm{CE} / \mathrm{g}$ of DW) samples from Machew and thorn-containing (7.50 mg CE/g of DW) samples from Mekhoni compared to the data reported by Dib et al. [15].

\section{Total tannins}

The total tannin content of the cladodes varies in the range 9.00-41.2 mg GAE/g of DW across the different sampling areas and varieties (Table 2 and 3). Comparing with the reported result by Dib et al. [15], significantly higher concentrations of tannins have been obtained in this study.

The content of total tannin varied significantly among samples of thorn-less variety collected from different areas (Table 2). This trend is similar to total flavonoids and polyphenols. Results from one-way ANOVA showed that the total tannin content are significantly higher in samples of thorn-containing cladodes from Addishihu district $(41.2 \mathrm{mg}$ GAE/g of DW) than samples from any other districts. For the thorn-less variety, the highest concentration of total tannin was found in samples from Adigrat (25.6 mg GAE/g of DW), while the lowest concentration was found in samples from Machew (9.00 mg GAE/g of DW).

Application of paired t-test on the overall mean total tannin contents of samples collected from the different areas revealed the presence of significant variations between thorn-less (15.9 GAE/g of DW) and thorn-containing (21.4 GAE/g of DW) varieties (Figure 1). When the two varieties were compared within each of the sampling areas, no significant difference was observed between thorn-less sample and thorn-containing samples from Machew and Makhoni districts, while the other pairs were found to be greatly varied.

\section{Antioxidant activities}

Antioxidant activities of plants are mainly attributed to the active compounds present in them. This can be due to the high percentage of main constituents, but also to the presence of other 
constituents in small quantities or to synergy among them. In this study, the antioxidant activities of cladodes ( $O$. ficus-indica) were determined by the method of DPPH radical scavenging assay. The results were compared with ascorbic acid as a reference antioxidant compound. The results are summarized in the Table 4 and 5, respectively, for thorn-less and thorn-containing varieties of cladodes samples.

Table 4. Antioxidant activities of thorn-less cladode of O. Ficus-indica*.

\begin{tabular}{|l|c|c|}
\hline Sampling area & Concentration in mg AAE/g of DW & Average \% inhibition \pm SD \\
\hline Addishihu & 1.73 & $83.5 \pm 2.9^{\mathrm{a}}$ \\
\hline Adigrat & 1.48 & $73.6 \pm 5.4^{\mathrm{b}}$ \\
\hline Machew & 0.55 & $59.3 \pm 1.2^{\mathrm{c}}$ \\
\hline Mekhoni & 0.97 & $85.8 \pm 0.7^{\mathrm{a}}$ \\
\hline
\end{tabular}

"Similar letters within a column indicates absence of significant difference.

Table 5. Antioxidant activities of thorn-containing cladodes of O. Ficus-indica* ${ }^{*}$

\begin{tabular}{|l|c|c|}
\hline Sampling area & Concentration in mg AAE/g of DW & Average \% inhibition \pm SD \\
\hline Addishihu & 1.72 & $83.0 \pm 0.4^{\mathrm{a}}$ \\
\hline Adigrat & 0.90 & $64.4 \pm 6.2^{\mathrm{b}}$ \\
\hline Machew & 0.80 & $78.7 \pm 1.9^{\mathrm{c}}$ \\
\hline Mekhoni & 1.23 & $85.8 \pm 1.2^{\mathrm{a}}$ \\
\hline
\end{tabular}

*Similar letters within a column indicates absence of significant difference.

Generally, free radical scavenging and antioxidant activity of phenolics (e.g. flavonoids, tannins) mainly depends on the number and position of hydrogen-donating hydroxyl groups on the aromatic ring of the phenolic molecules, and is also affected by other factors, such as glycosylation of aglycones, other H-donating groups (-NH, -SH), etc. For example, flavonolaglycones such as quercetin, myricetin, and kaemperol, containing multiple hydroxyl groups, have higher antioxidant activity than their glycosides such as rutin, myricitrin and astragalin.

The cladode samples have good antioxidant activity, ranging from 59.3-85.8\% inhibition compared to ascorbic acid (Table 4 and 5). If evaluated in terms of ascorbic acid antioxidant activity the equivalent values ranged from $0.548-1.73 \mathrm{mg} \mathrm{AAE} / \mathrm{g}$ of DW. The results clearly show that cladodes of $O$. ficus-indica could be used as an alternative source among vegetables in terms of antioxidant activity.

Significant variations in the antioxidant activities of cladodes of the same variety have also been observed among some of the sampling areas (Table 4 and 5). The significant difference among the antioxidant activities of the cladode samples is supposed to the effect of ecological parameters like climatic conditions and physiochemical nature of the soil beside cultivar variation.

Correlation between total polyphenol, tannin and flavonoid contents of the cladodes and antioxidant activity were analyzed. A direct correlation between antioxidant activity and polyphenol, tannin and flavonoid contents failed to demonstrate by linear regression analysis $\left(\mathrm{r}^{2}\right.$ $=0.20-0.80$ ). This lack of relationship is in agreement with the literature [31]. It is known that only phenolic compounds with a certain structure and particularly hydroxyl position in the molecule can act as proton donor and show radical scavenging activity [32].

Comparison of total polyphenol, total tannin and total flavonoids content of the Ethiopian cladodes of $O$. ficus-indica with that from other countries is given in Table 6. The total polyphenol and total flavonoid contents of the Ethiopian cladodes are comparable to that of the Algerian cladodes. However, the Ethiopian cladodes contained higher total tannin than the Algerian cladodes. In addition, the Ethiopian cladodes contained much higher total polyphenol 
Phenolic composition and antioxidant activities of cladodes of two varieties of cactus pear 355

and total tannin than the Spanish cladodes. These variations may be due to differences in geographical locations and climatic conditions.

Table 6. Comparison between the total polyphenol, total tannin and total flavonoid content of the Ethiopian cladodes with that from other countries.

\begin{tabular}{|l|c|c|c|c|}
\hline $\begin{array}{l}\text { Country of } \\
\text { origin }\end{array}$ & $\begin{array}{c}\text { Total polyphenol } \\
\text { in mg GAE/g DW }\end{array}$ & $\begin{array}{c}\text { Total tannin in } \\
\text { mg GAE/g DW }\end{array}$ & $\begin{array}{c}\text { Total flavonoid in } \\
\text { mg CE/g DW }\end{array}$ & Reference \\
\hline Ethiopia & $18.0-71.4$ & $9.00-41.2$ & $6.40-25.0$ & Present study \\
\hline Algeria & 26.7 & 6.40 & 11.9 & {$[15]$} \\
\hline Spain & 5.70 & - & - & {$[30]$} \\
\hline Spain & 3.80 & - & - & {$[30]$} \\
\hline
\end{tabular}

\section{CONCLUSION}

In this study, we report the results of the analysis of the two varieties of Ethiopian cladodes of Opuntia ficus-indica for their total polyphenol, tannin and flavonoid contents and antioxidant activities for the first time. The total polyphenol, tannin and flavonoid contents of the cladodes ranged from 18.0-71.4 mg GAE/gDW, 9.00-41.2 mg GAE/g DW and 6.40-25.0 mg CE/g DW, respectively. The antioxidant activities of the cladode samples were in the range of $0.55-1.73$ mg AAE/g DW. Generally, thorn-containing cladodes samples contained significantly higher total polyphenol, flavonoid and tannin as compared to the thorn-less variety grown in the same area. Furthermore, the geographical origin has been found to have significant effect on the phenolic composition of the cladodes. Compared to other leafy vegetables, Ethiopian cladodes of $O$. ficus-indica are rich in phenolic compounds with good antioxidant activities. Thus, this vegetable can be considered as easily accessible and valuable natural sources of antioxidants and dietary supplements.

\section{ACKNOWLEDGEMENTS}

The authors are grateful to the Department of Chemistry, College of Natural Sciences, Addis Ababa University, Addis Ababa, Ethiopia, for providing laboratory facilities and financial support. Kiros Haile is thankful to Wolayta Sodo University (Ethiopia) for sponsoring his study.

\section{REFERENCES}

1. Hollman, P.C.H.; Hertog, M.G.L.; Katan, M.B. Food Chem. 1996, 57, 43.

2. Dai, J.; Mumper, R.J. Molecules 2010, 15, 7313.

3. Sudjaroen, Y. Thai Cancer J. 2009, 29, 126.

4. Grotewold, E. The Science of Flavonoids, Springer: New York; 2006; p 274.

5. Piga, A. J. PACD 2004, 9.

6. Brutsch, M.O. J. Prof. Assoc. Cactus Dev. 1997, 130.

7. Edward, S.; Demissew, S.; Tadesse, M. Flora of Ethiopia and Eritrea, Vol. 2, The National Herbarium, Biology Department, Science Faculty, Addis Ababa University, Ethiopia and The Department of Systematic Botany, Uppsala University, Uppsala, Sweden; 2000.

8. Aregahegn, A.; Chandravanshi, B.S.; Atlabachew, M. Acta Hort. (ISHS) 2013, 979, 117.

9. Gebreegziabher, Z.; Tsegay, B.A. Afr. J. Food Agric. Nutr. Dev. (AJFAND) 2015, 15, 10406.

10. Medina, E.M.; Rodr1' guez, E.M.; Romero, C. Food Chem. 2007, 103, 38.

11. Park, E.H.; Kahng, J.H.; Lee, S.H.; Shin, K.H. Fitoterapia 2001, 72, 288. 
12. Roman-Ramos, R.; Flores-Saenz, J.L.; Alarcon-Aguilar, F.J. J. Ethnopharmacol. 1995, 48, 25 .

13. Jana, S. J. Eng. Res. Stud. 2012, 3, 60.

14. Khoddami, A.; Wilkes, M.A.; Roberts, T.H. Molecules 2013, 18, 2328.

15. Dib, H.; Beghdad, M.C.; Belarbi, M.; Seladji, M.; Ghalem, M. Int. J. Med. Pharm. Sci. 2013, 3, 147 .

16. Contreras-Padilla, M.; Pe'rez-Torrero, E.; Margarita, I. J. Food Comp. Anal. 2011, 24, 38.

17. Rodríguez-Félix, A.; Villegas-Ochoa, M.A. J. Prof. Assoc. Cactus Develop. 1997, 2, 142.

18. OÂ'Connor, C.J.; Sun, D.; Smith, B.G.; Melton, L.D. J. Food Sci. 2003, 68, 1093.

19. Lee, S.; Chung, S.; Lee, I. Food Sci. 2006, 71, S293.

20. Bizuayehu, D.; Atlabachew, M.; Ali, M.T. Springerplus 2016, 5:412. DOI: 10.1186/s40064016-2056-1.

21. Blahova, E.; Teterova, B.E.; Fabulova, A. J. Liquid Chromatogr. Related Technol. 2004, 27, 31.

22. Djeridane, A.; Yousfi, M.; Nadjemi, B.; Boutassouna, D.; Stocker, P.; Vidal, N. Food Chem. 2006, 97, 654.

23. Zhishen, J.; Mengcheng, T.; Jianming, W. Food Chem. 1999, 64, 555.

24. Marinova, D.; Ribarova, F.; Atanassova, M. J. Univ. Chem. Technol. Metal. 2005, 40, 255.

25. Atlabachew, M.; Chandravanshi, B.S.; Redi, M. Int. J. Food Prop. 2014, 17, 45.

26. Yeddes, N.; Jamila, K.; Guyot, C.S.; Sotin, H.; Ayadi, M.T. Antioxidants 2013, 2, 37.

27. Proestos, C.; Lytoudi, K.; Mavromelanidou, O.K.; Zoumpoulakis, P.; Sinanoglou, V.J. Antioxidants 2013, 2, 11.

28. Skerget, M.; Kotnik, P.; Hadolin, M.; Hras, A.R.; Simonic, M.; Knez, Z. Food Chem. 2005, 89, 191.

29. Zheng, W.; Wang, S.Y. J. Agric. Food Chem. 2001, 49, 65.

30. Ramirez-Moreno, E.; Córdoba-Díaz, D.; Sánchez-Mata, M.C.; Díez-Marqués, C.; Goñi, I. Food Sci. Technol. 2013, 51, 296.

31. Lizcano, L.J.; Bakkali, F.; Ruiz-Larrea, B.; Ruiz-Sanz, J. Food Chem. 2010, 119, 1566.

32. Rice-Evans, C.A.; Miller, N.J.; Paganga, G. Free Radical Biol. Med. 1996, 20, 933. 